\title{
Helminth fauna of Spiny Tailed Lizard, Darevskia rudis (Bedriaga, 1886) (Sauria: Lacertidae) from Turkey
}

\author{
S. BIRLIK' ${ }^{1}$, H. SAMI YILDIRIMHAN' ${ }^{1}$, Ç. ILGAZ2,3, Y. KUMLUTAŞ²,3

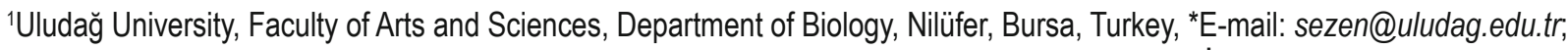 \\ ${ }^{2}$ Dokuz Eylül University, Faculty of Science, Department of Biology, 35160, Buca-Izmir, Turkey; \\ ${ }^{3}$ Dokuz Eylül University, Fauna and Flora Research Centre, 35610, Buca-Izmir, Turkey
}

Article info

Received November 10, 2017 Accepted November 22, 2017

\section{Summary}

The present study investigated the composition of helminth parasites of Darevskia rudis, Spiny Tailed Lizard from Turkey. One hundred and two samples $(49 \circ+$, 53 $\hat{\jmath})$ from the Tokat, Trabzon, Rize, Gümüşhane and Artvin Provinces were collected and examined for helminth parasites. New host and locality records were recorded. As a result of the present study, seven species of Nematoda, Skrjabinodon medinae, Spauligodon sp., Spauligodon carbonelli, Spauligodon aloisei, Skrjabinelazia hoffmanni, Strongyloides darevsky, Oswaldocruzia filiformis; one species of Cestoda, Mesocestoides spp. (tetrathyridium) and one species of Acanthocephala Sphaerirostris scanensis were reported from the lizard samples. Sp. carbonelli and Sphaerirostris scanensis are here recorded for the first time in Turkey. D. rudis is the new host recorded for Sk. medinae, Spauligodon sp., Sp. carbonelli, Sp. aloisei from Nematoda, Mesocestoides spp. from Cestoda and Sphaerirostris scanensis from Acanthocephala. This host has been studied for the first time for the helminth parasites from the Tokat and Gümüşhane Provinces. There is, to our knowledge, only one report of helminthes for D. rudis in Turkey.

Keywords: Darevskia rudis, Helminth, Cestoda, Nematoda, Acanthocephala, Turkey

\section{Introduction}

Caucasian rock lizards (Darevskia spp.) are small lacertids from western Asia and south-eastern Europe. Darevskia rudis, Spiny Tailed Lizard, (Bedriaga, 1886) is a common species which occurs in Turkey (including northern Anatolia and the Middle Taurus Mountains), Georgia, Russia and Azerbaijan. This species ranges from sea level to $2400 \mathrm{~m}$ a.s.l., inhabiting rocky areas in temperate forests but it may also occurs in montane-steppe habitats and on the walls of buildings and other human structures (Baran et al., 2012; Arribas et al., 2013).

Both domestic and wild animals are hosts of a wide variety of parasitic species therefore some helminth parasites studies have been carried out in our country, especially for lacertid lizards. In Turkey, there are 39 species of lizards belonging to family Lacertidae. The species which have been studied for their helminth fauna are: Lacerta viridis (Schad et al., 1960), Podarcis tauricus (Schad et al., 1960), Parvilacerta parva (Saygı \& Olgun, 1993), Anatololacerta danfordi (Gürelli et al., 2007), Lacerta trilineata (Yıldırımhan et al., 2011), Eremias pleskei, E. strauchi, E. suphani (Düsen et al. 2013), Apathya cappadocica (Birlik et al., 2015), Darevskia rudis (Roca et al., 2015a), Darevskia uzzelli, D. bendimahiensis and D. sapphirina (Roca et al., 2015b), D. clarkorum, D. raddei, D. parvula, D. valentini, D. armeniaca, D. unisexualis (Roca et al., 2016), Phoenicolacerta laevis (Birlik et al., 2016), Acanthocadtylus harranensis, A. schreiberi, Mesalina brevirostris (Düşen et al., 2016) and Iranolacerta brandtii (Birlik et al., 2017).

To our knowledge, there is only one report of specific helminths

\footnotetext{
$\overline{* \text { - corresponding author }}$
} 
in Darevskia rudis. The first study was conducted by Roca et al. (2015a). This is the second helminth study of this host in Turkey. Our objective is to gather information about the $D$. rudis helminth fauna and report on the differences between helminth species and present new locations of occurrence for the parasites.

\section{Material and Methods}

We examined $102 D$. rudis specimens, of which 49 were adult females (SVL: $42.6 \pm 2.3$ ), and 53 adult males (mean snout-vent length: $57.85 \pm 9.25$ with a range from 31.61 to 82.98 ). Lizards were captured by hand from different localities of the Tokat, Trabzon, Rize, Gümüşhane and Artvin Provinces (Fig. 1). Lizard specimens were anesthetized with ether, fixed with a $96 \%$ ethanol injection, and deposited in $96 \%$ ethanol. The body cavity of the lizards was opened, and the digestive tract removed. The oesophagus, stomach, small and large intestine and lungs were opened and examined for helminths under a dissecting microscope. The Nematodes were killed in hot saline solution, fixed in $70 \%$ ethanol, and mounted in glycerol. For the morphological examination, the helminth species were cleared gradually in glycerin. Cestodes were fixed in $70 \%$ ethanol, stained with iron-carmine as described by Georgiev et al. (1986), cleared in clove oil, and mounted in Entellan. The parasites were identified, when possible, to species, and the number and location of the individuals of each species were recorded. Helminth identification was based on keys given by Yorke and Maplestone (1926), Schmidt (1986), Yamaguti (1961,1963), Baker (1987), Petter and Quentin (1976), Anderson (2000). Helminth voucher specimens were deposited in the Uludağ University, Department of Biology, Bursa, Turkey; lizard specimens were deposited in the Dokuz Eylül University, Department of Biology, İzmir, Turkey. Prevalence, mean intensity and mean abundance were determined according to Bush et al. (1997). Specifically, prevalence is the percentage infected of individuals, mean intensity is the estimated number of parasites per infected individual, measured in specimens per infected animal and finally mean abundance is the estimated number of parasites per total number of examined host, measured as specimens per analysed animal.

\section{Results}

Fifty-six lizards were infected (55\%) and nine species of helminths were identified (Table 1): seven species of Nematoda, Skrjabinodon medinae, Spauligodon sp., Spauligodon carbonelli, Spauligodon aloisei, Skrjabinelazia hoffmanni, Strongyloides darevsky, Oswaldocruzia filiformis; one species of Cestoda, Mesocestoides spp. (tetrathyridium) and one species of Acanthocephala Sphaerirostris scanensis. In total 175 individuals of nine parasite species were collected from 56 of the 102 Spiny-Tailed Lizards examined.

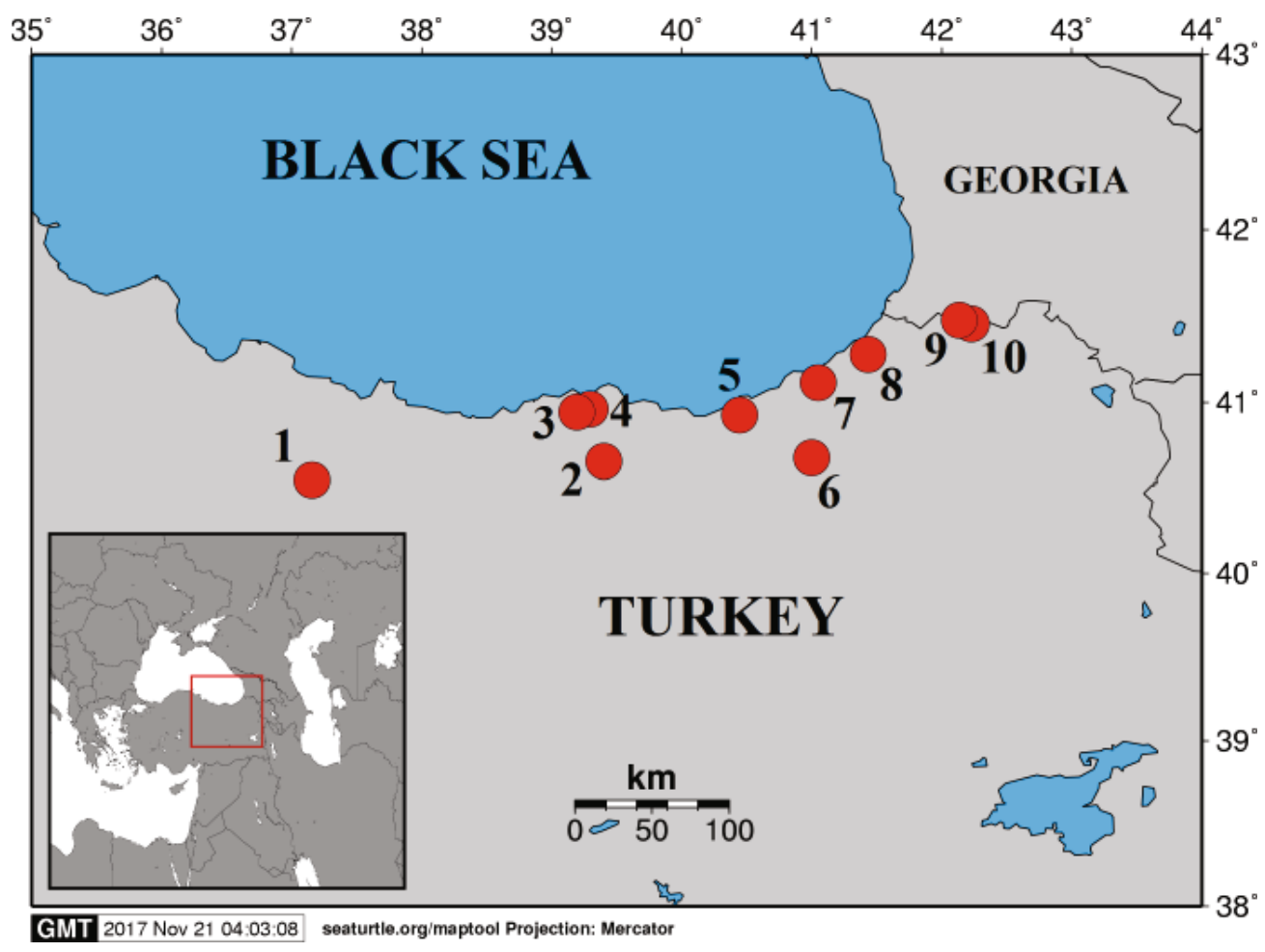

Fig. 1. The localities of host populations of Darevskia rudis (1. Karacaören, Başçitlik, Tokat; 2. Zigana Pass, Gümüşhane; 3. Şalpazarı, Trabzon; 4. between Tonya and Vakfıkebir 10. km, Trabzon; 5. Kalkandere, Rize; 6. Ovit Pass, Rize; 7. Köprüköy, Rize; 8. Dülgerli Village, Ortacalar, Arhavi, Artvin; 9. Papart Plateau; 10. Meydancık Village, Şavşat, Artvin 
There were nine helminth species represented in the lizards but no individual host harbored more than three helminth species. Of the infected lizards, 40 harbored one species of helminth, 15 harbored two species, one harbored three species. In this study, $D$. rudis is the new host record for Sk. medinae, Spauligodon sp., Sp. carbonelli, Sp. aloisei from Nematoda, Mesocestoides spp. from Cestoda and Sphaerirorstris scanensis from Acanthocephala. This host has been studied for the first time for helminth parasites from Tokat and Gümüşhane provinces. Sp. carbonelli and Sphaerirostris scanensis are recorded for the first time in Turkey. Prevalence, mean intensity and mean abundance of helminth species found in lizards were given in Table 1. al., 2002; Murvanidze et al., 2008). Moreover, unidentified Strongyloides spp. have also been reported in these reptiles (Perera et al., 2013). Although many species of Strongyloides show a low intensity of infection, higher prevalences of $S$. darevskyi (up to $75 \%$ ) with variable intensities of infection $(1-55)$ were found in some populations of Darevskia spp. from Transcaucasia (Sharpilo, 1973, 1976). In addition to the type host $D$. saxicola (Eversmann, 1884), S. darevskyi was reported in D. armeniaca (Méhely, 1909), D. rostombekovi (Darevsky, 1957) and D. rudis (Bedriaga, 1886). This is the third record of this species in Turkey. The first one was reported in $D$. rudis by Roca et al. (2015a), the second is from D. armeniaca by Roca et al. (2016).

Table 1. Prevalence, mean intensity and mean abundance.

\begin{tabular}{ccccc}
\hline Helmint Species & Site of infection & Prevalence (\%) & Mean intensity & Mean abundance \\
\hline Nematoda & & & & \\
Skrjabinodon medinae & Small intestine & 33.33 & 2.2 & 0.73 \\
Spauligodon sp. & Small intestine & 4.9 & 2 & 0.09 \\
Spauligodon carbonelli & Small intestine & 9.8 & 2.2 & 0.21 \\
Spauligodon aloisei & Small intestine & 2.94 & 1.33 & 0.03 \\
Strongyloides darevsky & Small intestine & 10.78 & 4.18 & 0.45 \\
Skrjabinelazia hoffmanni & Small intestine & 0.98 & 1 & 0.009 \\
Oswaldocruzia filiformis & Small intestine & 1.96 & 2.5 & 0.04 \\
Acanthocephala & & & & 0.019 \\
Sphaerirostris scanensis & Small intestine & 1.96 & 1 & \\
\hline
\end{tabular}

\section{Discussion}

This study is the second helminth study on $D$. rudis specimens inhabited in Turkey. The First study was conducted by Roca et al. (2015a) on lizard specimens from the Ardahan, Artvin, Rize, Trabzon, Bursa, Düzce, Zonguldak, Karabük, Bolu and Bartın Provinces. In that study, one cestode Nematotaenia tarentolae and four nematode species, Spauligodon saxicolae, Skrjabinelazia hoffmanni, Oswaldocruzia filiformis and Strongyloides darevskyi were reported.

In the present study, specimens collected from Tokat, Trabzon, Rize, Gümüşhane and Artvin Proviences were studied. We found additional helminth species. These are Sk. medinae, Sp. carbonelli, Sp. aloisei, one species of Cestoda, Mesocestoides spp. (tetrathyridium) and one species of Acanthocephala, Sphaerirostris scanensis. Also, one species of Nematoda was identified as genus level Spauligodon sp.

In both studies, only three nematode species have been found in common. These species are Strongyloides darevsky, Skrjabinelazia hoffmanni and Oswaldocruzia filiformis. At present, S. darevsky is a Darevskia specialist. Strongyloides spp. have been recorded in different reptile hosts worldwide, including the species $S$. cruzi Rodrigues, 1968, S. ophiusensis Roca \& Hornero, 1992 and S. darevskyi Sharpilo, 1976 described from lizards (Rodrigues, 1968, 1970; Sharpilo, 1973, 1976; Roca \& Hornero, 1992; Khanum et
In Turkey, reports of Strongyloides spp. in lizards are scarce. This species was reported from two host in Turkey: $D$. rudis (Roca et al. 2015a) and D. armeniaca (Roca et al. 2016). Strongyloides darevskyi is in fact a true Darevskia specialist since it has been recorded only in species of this genus (Roca et al., 2016).

Skrjabinelazia Sypliaxov, 1930 (Seuratidae: Skrjabinelaziinae) (see Chabaud, 1978) is a rarely reported nematode genus (Baker, 1987) which is parasitic in the insectivorous saurians, the Gekkonidae and Lacertidae, and exceptionally in the Iguanidae (see Freitas, 1940), Scincidae (see Goldberg \& Bursey, 1995) and Gerrhosauridae (see Caballero, 1968). Males of Skrjabinelazia are smaller than females and their lifespan is probably shorter; they are often scarce compared to females (Chabaud et al., 1988; Freitas, 1940). The nematode $S$. hoffmanni is a generalist species that has been recorded in some genera of Palaearctic lacertid lizards, such as Podarcis, Darevskia and Lacerta. This is the third record of $S$. hoffmanni in Turkey, other reports are from Anatololacerta danfordi (Gürelli et al., 2007) and D. rudis (Roca et al., 2015a). Oswaldocruzia filiformis belongs to the Order Strongylida, Family Molineidae: Head with cuticular vesicles, cuticle with transverse striations and longitudinal ridges, mouth with indistinct lips and a short esophagus. In the present study, both female and male specimens were found. This is the fifth report of 0 . filiformis in Turkey. Other records: Lacerta viridis and Podarcis tauricus, (Schad et al., 1960); Anguis fragilis (Düşen et al., 2010), Lacerta trilineata, 
(Yıldırımhan et al., 2011) and Darevskia rudis (Roca et al., 2015a). In addition to these common species, we also found some helminth species of Nematoda - Skrjabinodon mediane, Spauligodon aloisei, Sp. carbonelli and Spauligodon sp.

Skrjabinodon medinae lacks caudal alae and possesses a single pair of sessile pre-cloacal papillae. This is the fourth report of this species from our country. Others: Lacerta trilineata (Yıldırımhan et al., 2011), Apatyha cappadocica (Birlik et al., 2015) and Phoenicolacerta laevis (Birlik et al., 2016).

Species of Spauligodon are separated on the basis of the presence or absence of a spicule, the tail filament morphology, egg morphology, and geographical distribution. Currently, 52 species are assigned to Spauligodon (Bursey et al. 2014a; Pazoki \& Rahimian 2014). Based upon the zoogeographic regions described by Holt et al. (2013), 16 species is known from the Palaearctic realm. Spauligodon aloisei is the only species from the Palaearctic region which has prebulbar vulva position among all Spauligodon species. Previously, this species was reported from Iranolacerta brandthii (Birlik et al. 2017). This study is the second record of the species in Turkey.

The nematode $S$. carbonelli has been only recorded in the lizards Podarcis muralis, $P$. carbonelli and $P$. hispanica from the Iberian Peninsula (García-Adell \& Roca, 1988; Roca et al., 1989; Galdon et al., 2006), it may be considered a Podarcis specialist. Many Spauligodon spp. Found in Palaearctic region do not have a spicule. Only 5 of 22 species have spicule and Sp. carbonelli has a shorter $(15-35 \mu \mathrm{m})$ spicule than other male specimens with a spicule $(40-70 \mu \mathrm{m})$. Our male specimens have a short spicule $(22-28 \mu \mathrm{m})$ and a spiny tail $(1-5)$ and the females show postbulbar vulva. Sp. carbonelli is recorded for the first time in Turkey. We found both Spauligodon and Skrjabinodon species. This correlates with the usual pattern found in different European lacertid lizards, in which other Spauligodon species frequently share reptile hosts with members of the genera Skrjabinodon (but see Jorge et al., 2014) and Parapharyngodon (García-Adell \& Roca, 1988; Roca et al., 1986, 2009; Roca \& Hornero,1994).

Spauligodon saxicolae was found in a helminth study of $D$. rudis by Roca et al. (2015a) but we did not find this species in our lizard material. It is a nematode species of the Palaearctic region which have smooth tails in both male and female however males have no spicule. All of our nematode specimens found in this study have spiny tail and show spicules.

Mesocestoides spp., tetrathyridia are large, solid-bodied cysticercoids known only from the cyclophyllidean genus Mesocestoides are typically encountered embedded in the livers or coelomic mesenteries of their paratenic hosts. The genus has a worldwide distribution and is known from a great variety of amphibians and reptiles. It has been reported in the families Agamidae, Anguidae, Chamaeleonidae, Gekkonidae, Lacertidae and Scincidae (Witenberg, 1934; Hughes, 1940). The life cycle of species of Mesocestoides is believed to require 3 hosts: a vertebrate definitive host, a vertebrate second intermediate host, and an arthropod first intermediate host (Rausch, 1994). According to Specht and Voge (1965), the liver is the principal organ for natural infections in lizards. All the specimens found in this study were seen the liver. Tetrathyridia of the cyclophyllidean cestode, Mesocestoides sp. was reported previously from various lizards in Turkey Anatalocerta danfordi (Gürelli et al., 2007), Lacerta trilineata (Yıldırımhan et al., 2011), Apatya cappadocica (Birlik et al., 2015), Phoenicolacerta laevis (Birlik et al., 2016). This is the fifth report from lizards in Turkey.

Darevkia spp. show a lower prevalence of infection than the other continental Palaearctic rock lizards of the genus Podarcis. Roca et al. (2015a) associated these findings with the ecological characteristics of hosts and environment than in terms of the phylogeny of the lizard hosts.

Sphaerirostris scanensis (Lundström, 1942) Khokhlova, 1986, This species was recorded by Lundström (1942) from Turdus merula L., 1758 in Sweden. Comparing the morphometric data of the studied specimen with the original description, we found that the present species has a greater number of longitudinal rows of hooks - 28 versus 22 in the original description (Lundström, 1942) while the number of hooks per row and the morphology of the hook roots are comparable with those of $S$. scanensis. Another very similar species is Sphaerirostris turdi (Yamaguti, 1939) Golvan, 1956 described from thrushes and ortolans in Japan. The proboscis armament of this species consists of $26-34$ longitudinal rows of hooks with 11 - 14 hooks per row (Yamaguti, 1939) and 26 rows x 11 - 13 hooks per row according to Kugi (1988). Velikanov (1989) recorded encysted juveniles (larvae) of this species from Lichtenstein's toadhead agama (Phrynocephalus interscapularis (Lichtenstein, 1856)) in Turkmenistan. However there aren't any reports of this species in Turkey.

56 of $102(55 \%)$ were infected by several helminth species but when the number of host specimens (102) was taken into consideration, the actual number of helminth (175) found were less. The biodiversity of helminth species was higher than in the study by Roca et al. (2015). These differences may be derived from season. Our lizard samples were collected in July and August. Samples studied by Roca et al. (2015a) were collected in spring. In particular, herbivorous reptiles are infected by different Pharyngodonidae than carnivores. Petter and Quentin (1976) recognized two evolutionary lineages (each one of them with different genera) parasitising carnivorous or herbivorous reptiles. Moreover, the structure of helminth communities is richer and more diverse in herbivorous reptiles (Roca and Hornero, 1992). It has been suggested (see Roca 1999) that the monoxenous life cycle typical of the Pharyngodonidae favours the infection of herbivorous reptile hosts because they have more opportunities to accidentally eat eggs deposited in plants through faecal pellets. Moreover, the increase of plant matter consumed provides a suitable environment for the development of a more rich and abundant helminth fauna (Petter and Quentin, 1976; Roca, 1999; Roca et al. 2005).

Several aspects of the biology and the ecology of lizards such as, 
foraging modes, uses of microhabitats, body sizes, pregnancy, diet composition and ontogeny (Aho, 1990; Poulin, 1997) play a key roles in the acquisition of the associated helminth fauna. 13 Darevskia species inhabits in Turkey. Additional helminth studies are required to identify new helminth species, correlate the results with host characteristics and present new locality records. In summary, two new helminth records, six new host records and new geographic locality records are documented in this study.

\section{Acknowledgements}

The authors greatly acknowledge Mrs. Z. M. Dimitrova, Trakia University Department of Biology and Aquaculture Stara Zagora, Bulgaria for her valuable contribution on identifying Sphaeroristris scanensis. This study is a part of Sezen Birlik's PhD thesis supervised by Prof. Dr. Hikmet Sami Yıldırımhan. This work was supported by Uludağ University Scientific Research Coordination Unit. Project Number: OUAP(F)-2014/12.

\section{References}

Aно, J.M. (1990): Helminth communities of amphibians and reptiles: comparative approaches to understanding patterns and processes. In: Esch, G., Busch, A., Aно, J. (Eds) Parasite communities: patterns and processes. London, UK: Chapman and Hall, pp. $157-195$

Anderson, R.C. (2000): Nematoda Parasites of Vertebrates, their Development and Transmission. 2nd Edition, Walingford, UK, CABI Publishing, $650 \mathrm{pp}$.

Arribas, O.J., Ilgaz, C., Kumlutas, Y., Durmus, S.H., Avcl, A., Uzum, N. (2013): External morphology and osteology of Darevskia rudis (Bedriaga, 1886), with taxonomic revision of the Pontic and Small-Caucasus populations (Squamata: Lacertidae). Zootaxa., 3626, 401 - 428. DOI: 10.11646/zootaxa.3626.4.1

BAKER, M.R. (1987): Synopsis of the Nematoda Parasitic in Amphibians and Reptiles. Occasional Papers in Biology. Volume 11. St. John's Newfoundland, Canada: Memorial University of Newfoundland, $325 \mathrm{pp}$.

Baran, I., Ilgaz, C, Avcl, A., Kumlutas, Y., Olgun, K. (2012): Amphibians and Reptiles of Turkey. Ankara (TÜBITAK) 204 pp. (In Turkish)

BiRlik, S., Yildirimhan, H.S., Sumer, N., Kumlutas, Y., ILgaz, C., GucLU, O., Durmus, S.H. (2015): The helminth fauna of Apathya cappadocica (Werner, 1902) (Anatolian Lizard) from Turkey. Helminthologia, 52(4): 310 - 315. DOI: 10.1515/helmin-2015-0049

Birlik, S., Yildirimhan, H.S., Kumlutas, Y., Candan, K., Ilgaz, C. (2017): The first helminth study on Brandt's Persian Lizard Iranolacerta brandtii (De Filippi, 1863) (Squamata: Lacertidae) from Van province, Turkey. Helminthologia, 54(2): 174 - 178. DOI 10.1515/ helm-2017-0021

Birlik, S., Yildirimhan, H.S., Sumer, N., Kumlutas, Y., Ilgaz, C., Durmus, S.H., Guclu, O., Candan, K. (2016): Helminth fauna of
Phoenicolacerta laevis (Gray, 1838) (Lebanon Lizard) (Sauria: Lacertidae) from South-Eastern Turkey. Helminthologia, 53(3): 262 - 269. DOI 10.1515/helmin-2016-0016

Bursey, C.R., Goldberg, S.R., Grismer, L.L. (2014): A new species of Spauligodon (Nematoda: Oxyuroidea: Pharyngodonidae) in Cyrtodactylus bintangrensis (Sauria: Gekkonidae) from Peninsular Malaysia. J. Parasitol., 100(3): 317 - 322. DOI: 10.1645/13-410.1 Bush A.O, Lafferty K.D, Lotz J.M, Shostak A.W. (1997): Parasitology meets ecology on its own terms: Margolis et al. revisited. J. Parasitol., 83(4): 575 - 583. DOI: 10.2307/3284227

Chabaud, A.G., Bain, O., Poinar, G. O. (1988): Skrjabinelazia galliardi (Nematoda, Seuratoidea): compléments morphologiques et cycle biologique [Skrjabinelazia galliardi (Nematoda, Seuratoidea): further morphological data and life history]. Ann. Parasitol. Hum. Comp., 63: 278 - 284. DOI: 10.1051/parasite/1988634278 (In French)

Chabaud, A. G. (1978). Keys to genera of the superfamilies Cosmocercoidea, Seuratoidea, Heterakoidea and Subuluroidea. In: Anderson, R C., Chabaud, A.G., Willmott, S. (Eds) ClH Keys to the nematode parasites of vertebrates. Farnham Royal: Commonwealth Agricultural Bureaux, No.6., pp. 6 - 71

CABAllero, G. (1968). Contribution à la connaissance des nématodes de sauriens malgaches [Contribution to the knowledge of the nematodes of Malagasy saurians]. Ann. Parasitol. Hum. Comp., 16: 327 - 333. (In French)

Dusen, S., Kumlutas, Y., Ilgaz, C., Yaka, H., Karadayı, F. (2013): Helminth parasites of the three racerunner lizards: Eremias pleskei Nikolsky, 1905 (Pleske's Racerunner-Transcaucasian Racerunner), Eremias strauchi Kessler, 1878 (Strauch's Racerunner) and Eremias suphani Basoglu \& Hellmich, 1968 (Suphan Racerunner) collected from eastern part of Turkey. Helminthologia, 50(2): $108-$ 111. DOI: $10.2478 / \mathrm{s} 11687-013-0117-3$

Dusen, S. Aydogdu, A., Ugurtas, İ. H. (2010): Nematode parasites of the two limbless lizards: Turkish worm lizard, Blanus strauchi (Bedriaga, 1884) (Squamata: Amphisbaenidae), and slow worm, Anguis fragilis Linnaeus 1758 (Squamata: Anguidae), from Turkey. Helminthologia, 47(3):158 - 163 DOI 10.2478/s11687-010-0024-9 Dusen, S., Kumlutas, Y., Ilgaz, C., YaKagul, C. (2016): A helminthological research on three Lacertid lizards species: Acanthodactylus harranensis Baran et al, 2005, Acanthodactylus schreiberi Boulenger, 1878, and Mesalina brevirostris Blanford, 1874, collected from South and South-eastern regions of Turkey. Helminthologia, 53(2): 200 - 206. DOI: 10.1515/helmin-2016-0010

FREITAS, J. F. T. (1940): Sobre um interessante nematodeo parasito de reptil (Spiruroidea) [An interesting reptile parasite nematode (Spiruroidea)]. Mem. Inst. Oswaldo Cruz, 35, 603 - 605. DOI: 10.1590/S0074-02761940000300012 (In Portuguese)

Garcia-AdelL, G., RocA, V. (1988): Helminthofauna De Lacertidos de los Pirineos Centrales Ibericos [Helminthofauna De Lacertidos of the Iberian Central Pyrenees]. Rev. Ibér. Parasitol., 48:257 267 (In Spanish)

Georgiev, B.B., Biserkov, V.Y., Genot, T. (1986): In toto staining 
method for cestodes with iron acetocarmine. Helminthologia, 23: $279-281$

GoldBERG, S. R., BuRSEy, C. R. (1995): Gastrointestinal nematodes of two Australian skinks, Ctenotus regius and Ctenotus schomburgkii (Sauria: Scindidae). J. Helminthol. Soc. Wash., 62, 237 238

Gurelli, G., Gocmen, B., Ceetin-Dogan, T., Alpagut-Keskin, N. (2007): First record of Mesocestoides spp. Vaillant, 1863 Tetrathyridia (Cestoidea: Cyclophyllidea) in Anatolian lizard, Anatololacerta danfordi (Günther, 1876) in Turkey. N. West J. Zool., 3(2): 96 - 104 Holt, B.G., Lessard, M.K., Borregaard, S.A., Fritz, M.B., Araujo, D., Fabre, P.H., Graham, C.H., Gaves, G.R., Jonsson, K.A. (2013):An update of Wallaces's zoogeographic regions of the World. Science, 339: 74 - 78. DOI: 10.1126/science.1228282 Hughes, R.C. (1940): The genus Oochoristica Lühe, 1898. Am. Midl. Nat. J., 23: $368-380$

Jorge, F., Perera, A., Roca, V., Carretero, M.A., Harris, D.J., PoulIN, R. (2014): Evolution of alternative male morphotypes in oxyurid nematodes: a case of convergence? J. Evol. Biol., 27: 1631 - 1643. DOI:101111/jeb.12430

KugI G. (1988): Studies on the helminth fauna of vertebrates in Oita Prefecture. Part I.Avian helminths.184 pp.

Khanum, H, Sultana, R, Alam, M.S., Zaman, R.F. (2002): Endoparasitic helminth infection in Hemidactylus flaviviridis (Ruppel, 1835). Univ. J. Zool. Rajshahi Univ., 21: 17 - 19

Lundstrom A. (1942): Die Acanthocephalen Schwedens. Mit Ausnahme der Fischacanthocephalen von Süsswasserstandorten [The Acanthocephalen of Sweden. With the exception of fish acanthocephalas from freshwater locations]. Monographie. Lund, C.W. Lindström, 238 pp. (In German)

MurVanidZe, L, LOMIDZE, T, NIKolaISHVILI, K., JaNKARASHVILI, E. (2008): The annotated list of reptile helminths of Georgia. Proc. Inst. Zool. Tbilisi, 23: $54-61$

Pazokı, S., Rahimian, H. (2014): New species of Spauligodon Skrjabin, Schikhobalova and Lagodovskaja, 1960 and Thubunea Seurat, 1914 (Nematoda) from the gastroinstestinal tract of lizards in Iran. Syst. Parasitol., 89: 259 - 270. DOI: 10.1007/s11230-01499527-Y

Perera, A, MaiA, J.P., Jorge, F., Harris, D.J. (2013): Molecular screening of nematodes in lacertid lizards from the Iberian Peninsula and Balearic Islands using 18S rRNA sequences. J. Helminthol. 87: 189 - 194. DOI: 10.1017/S0022149X12000181

Petter, A.J., Quentin, J.C. (1976): CIH keys to the nematode parasites of vertebrates. No. 4 keys to genera of the Oxyuroidea. 1st ed. Commonwealth Agricultural Bureaux International, Farnham Royal, U.K., 30 pp.

PoulIN, R. (1997): Evolutionary Ecology of Parasites. Princeton University press. 360 pp.

RausCH, R.L. (1994): Family Mesocestoididae Fuhrmann, 1907. In: Khail, L.F., Jones, A., Bray, R.A. (Eds) Keys to the Cestode Parasites of Vertebrates. International Institute of Parasitology, Institute of CAB International, University Press, Cambridge, pp. 309 - 314
Roca, V., Lluch, J., Navarro, P. (1986): Contribucion Al Conocimiento De La Helmintofauna De Los Herpetos Ibericos I. Parasitos De Lacerta lepida Daudin, 1802 y Podarcis hispanica Steindachner, 1870 [Contribution to the Knowledge of the Helmintofauna of the Iberian Herpes I. Parasites of Lacerta lepida Daudin, 1802 and Podarcis hispanica Steindachner, 1870]. Rev. Ibér. Parasitol., 46: 129 - 136. (In Spanish)

Roca, V., Lopez-Balaguer, E., Hornero, M.J. (1989): Helmintofauna de Podarcis hispanica (Steindachner, 1870) y Podarcis bocagei (Seoane, 1884) (Reptilia: Lacertidae) en el Cuadrante Noroccidental de la Península Ibérica [Helmintofauna of Podarcis hispanica (Steindachner, 1870) and Podarcis bocagei (Seoane, 1884) (Reptilia: Lacertidae) in the Northwest Quadrant of the Iberian Peninsula]. Rev. Ibér. Parasitol., 49: 127 - 135 (In Spanish) Roca, V., Hornero, M.J. (1992): Strongyloides ophiusensis sp. n. (Nematoda: Strongyloididae), parasite of an insular lizard, Podarcis pityusensis (Sauria: Lacertidae). Folia Parasitol., 39: 369 - 373 RocA, V., HoRnero, M.J. (1994): Helminth infracommunities of Podarcis pityusensis and Podarcis lilfordi (Sauria: Lacertidae) from the Balearic Islands (western Mediterranean Basin). Can. J. Zool., 72: 658 - 664. DOI: 10.1139/z94-089

RocA, V. (1999): Relacion Entre Las Faunas Endoparasitas de Reptiles Y Su Tipo De Alimentacion [Relationship Between the Endoparasite Fauna of Reptiles and Their Type of Feeding]. Rev. Es. Herp.,13: 101 - 121 (In Spanish)

Roca, V. Carretero, M.A., Llorente, G.A., Montori, A., Martin, J.E. (2005): Helminth communities of two lizard populations (Lacertidae) from Canary Islands (Spain). Host Diet-Parasite Relationships. Amphib-Reptil., 26:535 - 542. DOI: 10.1163/156853805774806160

Roca, V., Jorge, F., Ilgaz, C., Kumlutas, Y., Durmus, S.H., CarRETERo, M.A. (2015a): The intestinal helminth community of the spiny-tailed lizard Darevskia rudis (Squamata,Lacertidae) from Northern Turkey. J. Helminthol., 90(2): 144 - 151. DOI: 10.1017/ S0022149X14000911

Roca, V., Jorge, F., Ilgaz, C., Kumlutas, Y., Durmus, S.H., CarreteRO, M.A. (2015b): Are the helminth communities from unisexual and bisexual lizards different? Evidence from gastrointestinal parasites of Darevskia spp. in Turkey. Acta Zool. Acad. Sci. Hung., 61(3): 279 - 288. DOI: 10.17109/AZH.61.3.6.2015

Roca, V. Jorge F., Ilgaz, C., Kumlutas, Y., Durmus, S. H., CarreteRO, M. H. (2016): Intestinal parasites of unisexual and bisexual lizards Darevskia spp. (Lacertidae) from Northeastern Anatolia. Helminthologia, 53, 3: 298 - 303. DOI 10.1515/helmin-2016-0021 RodRIGUES, H. O. (1968): Sobre nova espécie do gênero "Strongyloides" Grassi, 1879 (Nematoda, Rhabdiasoidea) [On new species of the genus "Strongyloides" Grassi, 1879 (Nematoda, Rhabdiasoidea]. Atas Soc. Biol. Rio de Janeiro, 12: 31 - 32 (In Portuguese) RodRIGUES, H.O. (1970): Estudo da fauna helmintológica de Hemidactylus mabouia (M. de J.) no Estado da Guanabara [Study of the helminthological fauna of Hemidactylus mabouia (M. de J.) in the State of Guanabara]. Atas Soc. Biol. Rio de Janeiro,12 (Suppl.): 15 - 23 (In Portuguese) 
SAYGI, G., Olgun, K. (1993): The nematode found in Dwarf Lizard (Lacerta parva) in Sivas province: Spauligodon. Turk. Parazitol. Derg., 17(1): 40 - 45

Schad, G.A., Kuntz, R.E., Wells, W.H. (1960): Nematode parasites from Turkish vertebrates. An annotated list. Can. J. Zool., 38: 949 - 963. DOI: 10.1139/z60-101

SchmidT, G.D. (1986): Handbook of Tapeworm Identification. CRC Press Inc., Boca Raton, Florida 675 pp.

SHARPILO, V. (1973): First findings of representatives from the genus Strongyloides Grassi, 1879 (Nematoda, Strongyloididae) in reptiles of Europe, Transcaucasia and Middle Asia. Dopov. Akad. Nauk URSR, Ser. B, 11: 1047 - 1050 (In Ukrainian)

SHARPILO, V. (1976): The parasitic helminths of reptiles of fauna of USSR. Naukova Dumka, Kiev (In Russian)

Specht, D., Voge, M. (1965): Asexual multiplication of Mesocestoides tetrathyridia in laboratory animals. J. Parasitol., 51: 268 272. DOI: $10.2307 / 3276097$

Velikanov, V. P. (1989): The role of amphibians and reptiles like intermediate and paratenic hosts of helminths in the conditions of the Turkmenian SSR. Izv. Akad. Nauk Turkm. SSR. Ser. Biol. Nauk, 6: 43 - 49 (In Russian)

Wittenberg, G.G. (1934): Studies on cestode genus Mesocestoides (with summaries in French, English and German). Arch. Zool. Ital., 20: 467 - 509

Yamaguti S. (1939) Studies on the helminth fauna of Japan. Part 29. Acanthocephala. Jap. J. Zool., 8: 317 - 351

Yamaguti, S. (1961): Systema Helminthum: The Nematodes of Vertebrates. Vol. III, Part II. Nematodes of Amphibians. Intersciences Publishers, London, England 679 pp.

Yamaguti, S. (1963): Systema Helminthum. Acanthocephala. Vol.V. Intersciences Publishers, London, England. 423 pp.

Yildirimhan, H.S., BurSey, C.R., Altunel, F.N. (2011): Helminth parasites of the Balkan green lizard Lacerta trilineata Bedriaga 1886 from Bursa, Turkey. Turk. J. Zool., 35(4): 519 - 535. DOI:10.3906/ zoo-0910-1

Yorke, W., Maplestone, P.A. (1926): The nematode parasites of vertebrates. London, UK, J. and A. Churchill pp 536 